\title{
Prevention of heart disease in women: Considerable challenges remain
}

\author{
Melissa Sherrod ${ }^{1}$, Nicholas McIntire Sherrod ${ }^{2}$, Mandy Tate Spitzer $^{2}$, Dennis Cheek ${ }^{1}$ \\ ${ }^{1}$ Harris College of Nursing, Texas Christian University, Fort Worth, USA \\ ${ }^{2}$ Cook Children's Healthcare System, Fort Worth, USA \\ Email: m.sherrod@tcu.edu
}

Received 23 May 2012; revised 21 June 2012; accepted 30 June 2012

\begin{abstract}
Although awareness of cardiovascular disease (CVD) as the leading cause of death among US women has improved over the past decade, factors such as obesity, untreated hypertension, diabetes and the lack of access to healthcare services prevent healthcare providers from making additional gains in the fight against heart disease. Due to demographic changes in the US, healthcare providers are beginning to acknowledge the challenge of providing quality care to a diverse population. Root causes of health care disparities include variations and lack of provider understanding of health beliefs, cultural values and preferences, and patients' inability to communicate symptoms in multiple languages. Barriers related to the patient, care provider and the healthcare system are discussed as well as ideas that will help address the challenges we face going forward.
\end{abstract}

Keywords: Cardiovascular Disease; Risk Factors; AHA Guidelines; Prevention; Women

\section{INTRODUCTION}

Significant progress has been made in the past decade in the treatment and prevention of cardiovascular disease (CVD) in women within the US. Because of significant investment by the scientific, medical and nursing community, age-adjusted death rate due to coronary heart disease (CHD) is one third what it was in 1980. Approximately $50 \%$ of this decline has been attributed to reducing major risk factors while the other half reflects changes in treatment modalities. While the news is positive overall, it is important to look at other factors that might inhibit additional progress.

This article will examine recent information from the American Heart Association (AHA) for the prevention of CVD in women, discuss remaining challenges, review disparities in healthcare delivery and present opportunities for professional response.

\section{NOT YOUR FATHER'S CARDIOVASCULAR DISEASE}

Although awareness of cardiovascular disease (CVD) as the leading cause of death among US women has improved from $30 \%$ in 1997 to $54 \%$ in 2009 , data from 2011 show that cardiovascular disease continues to claim more women's lives than cancer, chronic lower respiretory disease, Alzheimer disease, and accidents combined. In spite of recent gains, preventing heart disease continues to present a much greater challenge in women than in men [1].

One major factor contributing to this challenge is the increase in a woman's average body weight, with close to 2 out of every 3 US women over the age of 20 being overweight or obese. Current research suggests that the obesity epidemic is likely responsible for reversing the downward trend of the past 4 decades with a rise in CHD related deaths of US women ages 35 to 54 [1]. Additionally, obesity is one of the leading risk factors for type II diabetes mellitus, which currently affects more than 12 million US women and is commonly associated with an increased incidence of heart attack and stroke. Annually, 55,000 more women than men suffer a stroke, which is not only related to the type II diabetes mellitus epidemic, but also to risk factors unique to women such as pregnancy, hormone therapy, obesity and an increased prevalence of hypertension after age 65 . New recommendations from AHA stress that certain commonly accepted interventions are not useful and can actually be harmful for the prevention of CVD in women (Table 1). Although tmost recent AHA guidelines support the conclusion that the majority of recommendations for CVD prevention are similar for women and men, future guidelines will specifically consider interventions designed to reduce the incidence of CVD in women [2].

Another substantial challenge that prevents outcomes improvement is the fact that risk factors in certain vulnerable populations remain too high. One example among many is the prevalence of hypertension in U.S. black women, which from 1988 to 1994 through 1999 to 
Table 1. Interventions deemed not useful/effective which may be harmful for the prevention of CVD in women.

\begin{tabular}{|c|c|}
\hline $\begin{array}{l}\text { Menopausal } \\
\text { therapy }\end{array}$ & $\begin{array}{l}\text { Hormone therapy and selective estrogen-receptor } \\
\text { modulators (SERMs) should not be used for the } \\
\text { primary or secondary prevention of CVD. }\end{array}$ \\
\hline $\begin{array}{l}\text { Antioxidant } \\
\text { Supplements }\end{array}$ & $\begin{array}{l}\text { Antioxidant vitamin supplements (e.g., vitamin } \\
\text { E, C, and beta carotene) should not be used for } \\
\text { the primary or secondary prevention of CVD. }\end{array}$ \\
\hline Folic Acid* & $\begin{array}{l}\text { Folic Acid, with or without B } 6 \text { and B } 12 \\
\text { supplementation, should not be used for the } \\
\text { primary or secondary prevention of CVD. }\end{array}$ \\
\hline $\begin{array}{l}\text { Aspirin for } \mathrm{MI} \text { in } \\
\text { women }<65 \text { years } \\
\text { of age }\end{array}$ & $\begin{array}{l}\text { Routine use of aspirin in healthy women }<65 \\
\text { years of age is not recommended to prevent MI. }\end{array}$ \\
\hline
\end{tabular}

CVD indicates cardiovascular disease, MI, myocardial infarction. "Folic acid supplements should be used in childbearing years to prevent neural tube defects [1].

2002 was one of the highest in the world at 44\%. CVD rates are markedly higher among black women with 286.1 of every 100,000 as compared to 205.7 of every 100,000 white women. Educational and social outreach programs targeted to black women in particular are needed to reduce this disparity since lower rates of CVD awareness in this cohort have been documented [2,3].

Then there is the challenge of communicating with a diverse population of women throughout the US. We know that swift entry into the healthcare system increases positive outcomes, yet a recent national survey conducted by the American Heart Association showed only 53\% of women reported "calling 9-1-1" as the first thing they would do if they thought they were having a heart attack [4]. Because lack of awareness remains a barrier to optimal survival, patients must know what to do if symptoms appear and how to access the healthcare system immediately. As nurses, we are in the front lines for providing accurate, timely information to increase awareness and improve response times to a healthcare crisis.

\section{HOW TO ESTIMATE RISK}

In 2007, the AHA algorithm was adopted that stratified women into 3 categories: high risk, at risk and at optimal risk. Evidence since 2007 continues to support the risk classification algorithm and in 2011, the AHA defined a new concept of "ideal cardiovascular health". Ideal cardiovascular health is defined by the absence of clinical CVD and ideal levels of total cholesterol $(<200 \mathrm{mg} / \mathrm{dL})$, blood pressure $(<120 / 80 \mathrm{~mm} \mathrm{Hg})$, fasting blood glucose $(<100 \mathrm{mg} / \mathrm{dL})$, lean body mass index $\left(<25 \mathrm{~kg} / \mathrm{m}^{2}\right)$, abstinence from smoking, physical activity at recommended levels, and a dietary approach to stop hypertension eating pattern. When achieved into middle age, the pattern of "ideal cardiovascular health" has been associated with greater longevity, dramatic reductions for CVD events, greater quality of life in older adults and lower health care costs (Table 2) [1].

Pregnancy provides another unique opportunity to estimate a woman's lifetime risk of CVD when compared with their male counterparts. Women with a history of preeclampsia have approximately double the risk for subsequent ischemic heart disease, stroke, and venous thromboembolic events over the $5-15$ years following pregnancy. Because of this risk, healthcare professionals are strongly encouraged to take a careful and detailed history with older women that focuses on prior pregnancy complications, including those with a history of gestational diabetes mellitus, preeclampsia, preterm birth or birth of an infant small for gestational age [1].

\section{DIVERSITY, DISPARITIES: ONE SIZE DOES NOT FIT ALL}

Due to rapidly changing population shifts in the United States, healthcare professionals must consider the individuality of the patient in the clinical setting if we are to make additional gains in reducing CVD. Providers are aware of the well-recognized facets of diversity such as race, ethnicity, education and geographical location. Other facets of diversity such as age, language, culture, literacy, disability, frailty, socioeconomic status, occupational status, sexual orientation and religion are less well known. A better understanding of these facets of diversity may help reduce disparities in healthcare delivery. Disparities in healthcare delivery have been defined by the Institute of Medicine (IOM) as differences in treatment that are not justified by health condition differences or treatment preferences. According to the IOM, these disparities exist even when controlling for insurance status, socioeconomic status and co-morbidities. Root causes of disparities include variations and lack of provider understanding of health beliefs, cultural values and preferences, and the patient's inability to communicate symptoms in a language other than their own [5].

Although guidelines may be applied across all groups, it is important to recognize the higher prevalence of risk factors in certain racial and ethnic groups such as hypertension among black women or diabetes mellitus in women of Hispanic descent. Black females have the highest percentage of deaths due to CVD, a percentage similar to the mortality of white men. Asian/Pacific Islanders and White females follow close behind. Hispanic/Latino females and American Indian/Alaska Native females complete the list [6]. These disparities in cardiovascular disease and established risk factors demonstrate the need for heightened preventive efforts in the diverse female population. 
Table 2. Classification of CVD risk in women.

\begin{tabular}{|c|c|}
\hline Risk Status & Criteria \\
\hline $\begin{array}{c}\text { High Risk } \\
\text { ( } \geq 1 \text { high-risk status) }\end{array}$ & $\begin{array}{l}\text { Evidence of CHD } \\
\text { Evidence of cerebrovascular disease } \\
\text { Evidence of peripheral arterial disease } \\
\text { Abdominal aortic aneurysm } \\
\text { End-Stage or kidney disease } \\
\text { Diabetes Mellitus } \\
10 \text { year predicted CVD risk greater than or equal to } 10 \%\end{array}$ \\
\hline $\begin{array}{c}\text { At Risk } \\
(\geq 1 \text { major risk factor(s)) }\end{array}$ & $\begin{array}{l}\text { Poor diet } \\
\text { Physical inactivity } \\
\text { Obesity, central adiposity } \\
\text { Metabolic syndrome } \\
\text { History of preeclampsia, gestational diabetes or pregnancy-induced hypertension } \\
\text { Total cholesterol } \geq 200 \mathrm{mg} / \mathrm{dL}, \mathrm{HDL}-\mathrm{C}<50 \mathrm{mg} / \mathrm{dL} \text {, or treated for dyslipidemia } \\
\text { Cigarette smoking } \\
\text { Treated hypertension or } \mathrm{SBP} \geq 120 \mathrm{~mm} \mathrm{Hg}, \mathrm{DBP} \geq 80 \mathrm{~mm} \mathrm{Hg} \\
\text { Poor exercise capacity on treadmill test and/or abnormal heart rate recovery after stopping exercise } \\
\text { History of lupus or rheumatoid arthritis } \\
\text { Evidence of advanced subclinical atherosclerosis (e.g. coronary calcification, carotid plaque) }\end{array}$ \\
\hline $\begin{array}{l}\text { Ideal Cardiovascular health } \\
\text { (All of these) }\end{array}$ & $\begin{array}{l}\text { Total cholesterol }<200 \mathrm{mg} / \mathrm{dL} \text { (untreated) } \\
\mathrm{BP}<120 /<80 \mathrm{~mm} \mathrm{Hg} \text { (untreated) } \\
\text { Fasting blood glucose }<100 \mathrm{mg} / \mathrm{dL} \text { (untreated) } \\
\text { Body mass index }<25 \mathrm{~kg} / \mathrm{m}^{2} \\
\text { Non smoker } \\
\text { Physical activity at goal for adults: } \geq 150 \mathrm{~min} / \mathrm{wk} \text { moderate, } \geq 75 \mathrm{~min} / \mathrm{wk} \text { vigorous intensity or combination } \\
\text { Low fat, low sugar DASH like diet }\end{array}$ \\
\hline
\end{tabular}

\section{GLOBAL RECOMMENDATIONS}

Cardiovascular disease is not just a problem for US women. Current data documents the global scope of the problem; that heart disease is the leading cause of death for women in major developed countries as well as many of those countries with growing and emerging economies. This is not only of concern to women but also to the healthcare providers who often do not realize the significance of CVD among women [5].

Cardiovascular disease has become a global pandemic among women, with approximately $81 \%$ of all cardiovascular deaths in women occurring in the low- and middle-income countries with limited capacity for guideline development [7]. Because of the global threat of CVD, the 2011 American Heart Association emphasizes that these guidelines are applicable internationally. The World Health Organization and other international organizations have proposed specific measures for the evaluation of guidelines to provide appropriate international applicability. From the Global Program on Evidence for Health Policy-Guidelines for WHO Guideline, four criteria were presented for assessing the international utilization of specific guidelines: 1) efficacy and safety; 2) cost-effectiveness; 3) affordability; and 4) popu- lation benefits [3]. These criteria provide an important feature because most of the 2011 recommendations can be used in most countries or regions with or without slight modifications. Furthermore, the recommendations can be di- rectly applied to clinical practice. The risk classifi- cation can be applied by not only the healthcare provider, but also utilized for patient education [1].

\section{BARRIERS TO CHANGE}

While public awareness of CVD among men and women has improved since the last standards were released, preventive care outcomes continue to disappoint. Approximately $50 \%$ of Americans with hypertension are still not treated to goal while racial and ethnic disparities in the management of hypertension, DM, and lipids persist [1]. Previous studies support using scientific evidence and desired treatment strategies, noting that guidelines are fundamental to preventing and improving outcomes for patients with CVD. However, evidence points to three barriers that limit adherence to CVD prevention guidelines for women. These barriers relate to the patient, care provider and the healthcare system.

\subsection{The Patient}

An analysis of over 100 medical adherence studies shows that women are as likely to be non-adherent to medical therapies as men [7]. Patient resistance to behavioral change is a major factor noted in decreasing guideline adherence. To complicate matters, there is little research that gives the clinician practical advice on how to motivate women to initiate and maintain adherence to the guidelines. Improvement efforts will only be success- 
ful if women become more personally accountable for cardiovascular prevention in addition to depending on the healthcare system for help. To do that, they have to be convinced that their health matters and that their behaviors directly impact their health status.

\subsection{The Provider}

The new AHA guidelines look to the healthcare provider to improve health outcomes [8]. Physicians who lack the knowledge and skill in guideline implementation that would improve preventive care are given considerable attention. Barriers to prevention reported by physicians included lack of time to provide patient information and education, lack of organizational support, and patient resistance to change. Most physicians who reported time as a barrier were less likely to discuss smoking cessation with their female patients, thus losing an opportunity to improve outcomes for women who smoke [9]. Research has found that one dimensional interventions like brief initial patient education and traditional patient reminders are ineffective. The best interventions are multifaceted, interactive and include patient decision-making and feedback, activities that involve provider time, organizational support and patient acceptance [10].

\subsection{The Healthcare System}

While there is less research available to understand the best methods for implementing CVD prevention guidelines, there are some new ideas on the horizon. There has been improvement with guideline adherence in centers that implemented the get with the Guidelines program. In hospitals instituting this program, disparities in MI guidelines by gender, age, ethnicity and race narrowed over time. The AHA is now starting a Get With The Guidelines-Outpatient program and the American College of Cardiology is supporting quality improvement activities to increase physician implementation of the guidelines [11]. However, we are still lacking a robust evidence base for improving guideline adherence by addressing patient, provider and system-level barriers on a practical level. Although there is a lack of clarity on how to proceed within the healthcare system, quality improvement efforts are underway that focus on supporting what works: multidimensional interactive systems that increase accountability among all concerned: payer, provider and patient.

\section{WAYS TO ADDRESS THE CHALLENGES THAT REMAIN}

There are valid reasons people lack the willingness or ability to make the personal changes required to impact CVD. Research shows that patients with chronic diseases may see up to 16 different physicians annually. Lack of shared medical information makes care coordination difficult. Patients with low socioeconomic status, low literacy levels, depression, psychiatric illnesses, poor hearing or vision, poor cognitive function, lack of fluency in English, advanced age, and lack of confidence in Western medicine are often not capable of understanding complex instructions and explanations that require advanced reasoning and critical thinking skills. For others, lack of transportation and financial resources limit their ability to access the health care system and follow through with treatment plans [1].

Providing successful patient education is challenging for providers due to limited time for healthcare visits, patients with complex co-morbidities, lack of staff for teaching and follow-up, lack of training regarding counseling patients about behavior change, and lack of payment for prevention and education. Without reimbursement, patient education becomes a luxury that most clinicians cannot or will not provide.

While patients and providers present immense challenges for change, it is clear that effective implementation of national guidelines for the primary prevention of CVD requires a team-based approach to education, including the patient, family and all key healthcare professsionals. Ways to increase CVD prevention adherence, especially targeted toward women, include addressing family and caretaking activities, stress, sleep-deprivation, fatigue, and lack of personal time. Involving the patient and family in setting short-term achievable goals with frequent follow-up will also improve success [1].

The new guidelines call for a renewed focus on health education, including therapies that have proven to improve lifestyle and medication adherence. Such approaches include behaviorally based counseling, self-monitoring (i.e. blood pressure, weight, food records, and blood glucose $\operatorname{logs}$ ), group sessions and shared medical visits (e.g. newly diagnosed diabetics), computer-assisted reminders, and electronic communication to support behavioral change. Studies show that regardless of barriers, educational efforts make a difference in improved health and lifestyles for women and their family members [1].

\section{WHAT CAN NURSES DO TO HELP?}

While a discussion on barriers and challenges is important, the key to progress is identifying what is working and what we can do going forward. The most important thing to take away from this information is that nurses can and must be the agents of change. Ways to do this include assessing patient literacy and increasing the patient's understanding of the education provided by using materials and language that match their literacy level. Nurses must assess the patient's willingness to change. 
Designing a plan of care is an important first step, but the effectiveness of that plan must center on the patient's readiness for change and willingness to try new behaviors.

One way to improve multidisciplinary teamwork is to ensure that practitioners are accessing evidenced based data, rather than relying on outdated information that misinforms their clinical reasoning. Being an agent of change in your workplace and accessing new sources of information that challenge existing perspectives and barriers support new ways of thinking.

When patients are being seen by 16 different physiccians, or even by two, pull together as much data from these caregivers as possible. We can't accurately treat our patients if they're being told conflicting and competing information by healthcare providers who aren't in communication with one another. Encourage open communication between physicians and healthcare sites so that everyone on the healthcare team is basing his or her care on the whole picture, rather than that practitioner's specialty alone. By embracing our job as nurses to assess, communicate and educate, we can affect true change in the lives of our patients and perhaps begin to see a decrease in these alarming statistics.

\section{CONCLUSION}

While there has been an overall improvement in awareness of cardiovascular disease (CVD) as the leading cause of death among US women over the past decade, the medical and healthcare community continues to wage an uphill battle against obesity, untreated hypertension, diabetes and lack of access to the healthcare system, among other factors. All of these issues prevent healthcare providers from making substantial gains in the fight against heart disease. Demographic changes in the US have resulted in an acknowledgement by healthcare providers that offering quality care to a diverse population remains a considerable challenge due to the root causes of disparities, including lack of provider understanding of health beliefs, cultural values and preferences, a lack of multilingual providers and patients' inability to communicate symptoms in multiple languages. Barriers related to the patient, care provider and the healthcare system were discussed, as were ideas that aim to address the challenges we face going forward.

\section{REFERENCES}

[1] Mosca, L. (2011) Effectiveness-based guidelines for the prevention of cardiovascular disease in women-2011 update: A guideline from the American Heart Association. Circulation, 123, 1-21. doi:10.1161/CIR.0b013e31820faaf8

[2] Mosca, L. (2010) Twelve-year follow-up of American women's awareness of cardiovascular disease risk and barriers to heart health. Circulation: Cardiovascular Quality and Outcomes, 3, 120-127. doi:10.1161/CIRCOUTCOMES.109.915538

[3] Gholizadeh, L. and Davidson, P. (2008) More similarities than differences: An international comparison of CVD mortality and risk factors in women. Health Care Women International, 29, 3-22. doi:10.1080/07399330701723756

[4] AGREE Collaboration (2003) Development and validation of an international appraisal instrument for accessing the quality of clinical practice guidelines: The AGREE project. Quality and Safety in Health Care, 12, 18-23. doi:10.1136/qhc.12.1.18

[5] Institute of Medicine (2002) Unequal treatment: Confronting racial and ethnic disparities in health care. National Academies Press, Washington DC.

[6] Roger, V.L. (2011) Heart disease and stroke statistics2011 update: A report from the American Heart Association. Circulation, 123, e18-e209. doi:10.1161/CIR.0b013e3182009701

[7] DiMatteo, M.R. (2004) Variations in patients' adherence to medical recommendations: A quantitative review of 50 years of research. Medical Care, 42, 200-209. doi:10.1097/01.mlr.0000114908.90348.f9

[8] Doroodchi, H. (2008) Knowledge and attitudes of primary care physicians in the management of patients at risk for cardiovascular events. BMC Family Practice, 9, 42.

[9] Barnhart, J., et al. (2007) Physician knowledge levels and barriers to coronary risk prevention in women: Survey results from the Women and Health Disease Physician Education Initiative. Women's Health Issues, 17, 93-100. doi:10.1016/j.whi.2006.11.003

[10] Francke, A.L., et al. (2008) Factors influencing the implementation of clinical guidelines for health care professionals: A systematic meta-review. BMC Medical Informatics \& Decision Making, 8, 38 .

[11] Cohen, M.G. (2010) Racial and ethnic differences in the treatment of acute myocardial infarction: Findings from the get with the Guidelines-Coronary Artery Disease program. Circulation, 121, 2294-2301. doi:10.1161/CIRCULATIONAHA.109.922286 